\title{
OPTIMIZING THE SERVICE LIFE OF PLANT MACHINERY AND VEHICLES USING INFORMATION SYSTEM FOR MANAGEMENT OF ENGINEERING STATUS
}

\author{
Sergey Repin'1, Sergey Evtiulov², Jaroslav Rajczyk ${ }^{3}$ \\ 1,2 Saint Petersburg State University of Architecture and Civil Engineering, \\ Vtoraja Krasnoarmejskaja ul. 4, St. Petersburg, 190005, Russia. \\ ${ }^{3}$ Częstochowa University of Technology, \\ ul. Dabrowskiego 69, Czestochowa, 42-201, Poland. \\ ${ }^{1}$ repinserge@mail.ru, ${ }^{2}$ s.a.evt@mail.ru
}

\begin{abstract}
The paper contains results of studies of changes in performance of plant machinery and vehicles during operation: non-failure operating time, costs, revenue, profit and cost efficiency. It is shown that decrease of non-failure operating time and increase of operating costs can be described by the exponential law. Mathematical models based on changes of performance parameters were developed in order to determine optimum service life of machinery according to economic criteria. The paper describes application of an information system for collection and processing of data necessary for models.

Application of the developed method for determining of optimum service life would contribute to rational formation of machinery fleet.
\end{abstract}

Key words: plant machinery and vehicles, service life, operation, information system

\section{Introduction}

Operational management of complex facilities, such as plant machinery and vehicles, is a complicated task with many parameters. A whole class of automated information means, i.e. asset management systems (according to European classification, EAM systems - Enterprise Asset Management), was developed to assist in solving of this task. EAM systems provide collection and processing of operational information, automate maintenance and repair planning, and reveal the need for spare parts and other resources. One of directions of EAM system development is its intellectualization, i.e. development of an opportunity to improve production processes by supplying information systems with mathematical models describing dynamics of main parameters and processes.
Mathematical models for optimization of service life of machinery were developed at the Department of Plant Machinery and Vehicles of the Saint Petersburg State University of Architecture and Civil Engineering (SPSUACE) (Repin, 2015; Repin et al. 2012). Application of these models is performed by integrating them with one of the best Russian EAM systems - TRIM software - designed by specialists of Scientific Production Enterprise "SpetsTek" (Saint Petersburg) and adapted together with specialists of the SPSUACE for plant machinery and vehicles (Repin et al., 2008).

Integration is possible in two ways: exporting data to an external software module, and introduction of the software module directly into TRIM. The external software module may be presented by a program written in mathematical environment, for example, Excel, Mathcad, 
Statistica, etc. All necessary information is exported from TRIM to this program. This method is the most simple for implementation, but it requires additional software and training of users. Direct introduction of the software module into TRIM is connected with updating of the latter, but this method is more convenient to users, and therefore seems the most promising.

Models for optimization and prediction of service life of machinery by various parameters (economic, technical, and ecological) were developed. The paper describes the use of the most popular models for optimization of service life of machinery, which are economic models. Data on operating time of machinery, revenue and costs are necessary for analysis and prediction.

\section{Subject, tasks and methods}

The subject of the study is plant machinery and vehicles, technical and economic records (reliability, performance, and costs) of which vary depending on the service life.

The task of the paper is to develop methods for justification of service life of machinery on the basis of operational information.

Methods applied are statistical analysis and prediction.

\section{Results and discussion}

Description of models for determination of optimum service life of machinery

Values of records change with the aging of machinery (Smith, 2003; Bujaczek et al., 2013; Shao-Fei Jiang et al., 2014; Repin et al., 2016; Protasov, Nikolaychuk, 2011; Makhutov, Reznikov, 2015; Chernyavsky, Shadchin, 2010). Thus, for example, operating time reduces due to the increase of maintenance downtime, while operating costs $\left(Z_{\mathrm{var}}\right)$ rise by $1.5 \ldots 4 \%$ per year. These changes are described quite well (with the performance of $0.88 \ldots 0.92$ ) with the exponential dependence under parameter $\beta=0.012 \ldots 0.048$ per year -1 (Repin et al., 2016) $\left(\beta_{\mathrm{t}}\right.$ is aging by operating time, and $\beta_{z}$ is aging by costs):

where $T_{p}(t), T_{p}(1)$ is the total duration of machine uptime in the $t^{\text {th }}$ and the first year of operation respectively;

$$
\begin{aligned}
T_{P}(t) & =T_{P}(1) \cdot \exp \left(\beta_{t} \cdot t\right) \\
Z_{\text {var }}(t) & =Z_{\text {var }}(1) \cdot \exp \left(\beta_{z} \cdot t\right)
\end{aligned}
$$

$Z_{\text {var }}(t), Z_{\text {var }}(1)$ are variable components of costs (operating costs) in the tth and the first year of operation respectively; $t$ is the current age of the machine, year.

Operating time of the machine is the basis for calculating of revenue $B(t)$; operating time of the machine is determined by the total duration of machine uptime $T_{P}(t)$ during the accounting period (year).

There are two main options for getting revenue:

1) if the company owner of the machine leases it out, then

where $P_{\text {run.h. }}$ is the price of an hour of machine rent;

$$
B(t)=P_{\text {run.h. }} T_{P}(t)
$$

2) if the company owner uses the machine for production, then the revenue depends on performance of the machine $Q(t)$, production unit price $c$ and operating time $T_{P}(t)$ :

where $k_{u}$ is utilization factor of machine (operating time,

$$
B(t)=\sum Q(t) \cdot c \cdot T_{P}(t) \cdot k_{u}
$$

capacity, lading capacity, etc.).

Costs have a very complex structure. The following formula states a simplified expression of costs on maintenance and operation of machinery fleet:

Economists consider the first term as conditional-con-

$$
Z(t)=Z_{\text {const }}(t)+Z_{\text {var }}(t)
$$

stant costs that do not depend on the output volume (fulfilled machine hours) for the accounting period. $Z_{\text {const }}(t)$ is mainly the costs of machinery ownership. The second term is variable costs $Z_{\text {var }}(t)$ increasing in proportional to the output volume. These are the cost of machine operation. Costs are calculated according to regulatory documents. Thus, for example, it is recommended to use the Guidelines of the State Committee for Construction of Russia for construction and motor transport machinery (GOSSTROI ROSSII, 1999).

Profit $\Pi(t)$ is calculated as difference of revenue $B(t)$ and costs $Z(t)$ :

Optimum service life of machine can be determined

$$
\Pi(t)=B(t)-Z(t)
$$

by minimum specific cost accounted for a machine hour; maximum profit margin; and specified minimum level of cost efficiency $R_{\text {min }}$.

Specific costs modified to machine hour are determined by the following formula (Figure 1):

$$
z^{\prime}(t)=\frac{Z_{\text {const }}(t)+Z_{\text {var }}(t)}{T_{P}(t)}
$$

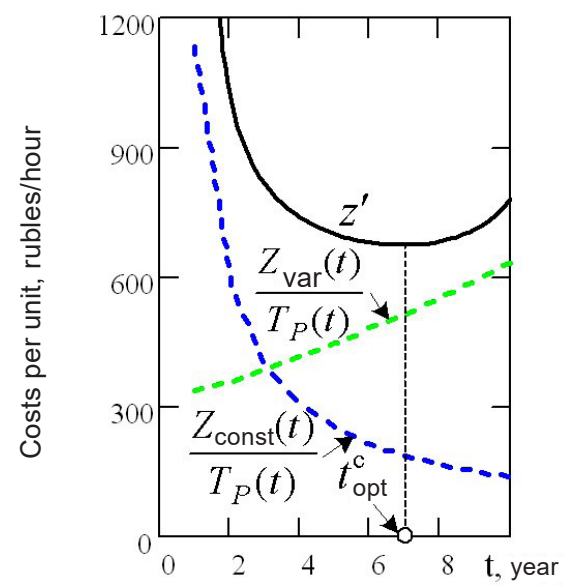

Figure 1. Change of specific costs for machine operation depend-

ing on its service life: $t_{o p t}^{c}$ is optimum service life of machine

Let us consider the dynamics of life cycle profit of machinery. As the machine ages, the value of revenue falls, because machine operating time per unit decreases according to formula (1). Costs increase too, in accordance 
with expression (2). Total revenues $S B(t)=\sum B(t)$ and total costs $S Z(t)=\sum Z(t)$ during the service life amount to the total (accumulated) profit from operation of the machine (Figure 2a):

where $C_{m}$ is the price of the machine.

Total profit chart $S \Pi(t)$ has four indicative points at time

$$
S \Pi(t)=-C_{m}+S B(t)-S Z(t),
$$

moments: $0, t_{o k}, t_{\max }^{\Pi}$ and $t_{S \Pi=0}$. At $t=0, S \Pi(t)=-C_{m}$. The value of total profit stays below zero until moment of payback $t_{o k}$. $S \Pi(t)$ reaches its maximum at $t_{\max }^{\Pi}$. At this moment, values of annual revenue and costs become equal. Operation of the machine must be stopped before time $t_{\max }^{\Pi}$

Further use of the machine will cause losses, and by time $t_{s \Pi}=0$ maintenance costs of the aged machine will consume all the profit.

Thus, the optimum service life of the machine is in the time range from $t_{o k}$ to $t_{\max }^{\Pi}$. More specifically, optimum service life can be predicted by the model of dynamics of accumulated profit margin (Figure $2 b$ ).
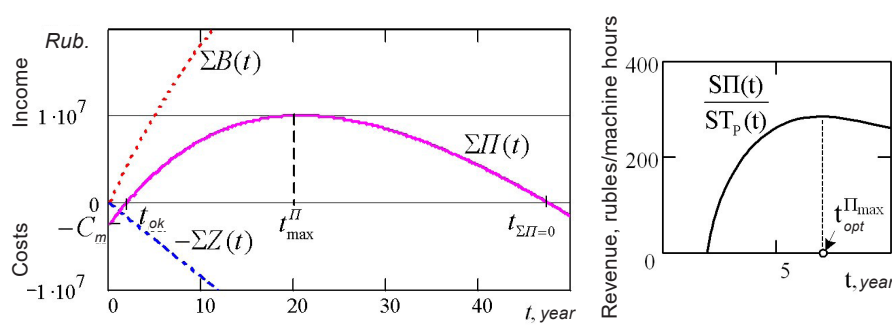

Figure 2. Dynamics of accumulated profit $S \Pi(t)$ (a) and profit margin (b) during the service life of the machine: $S B(t), S Z(t), S T_{p}(t)$ are accumulated revenue, costs and operation time; $C_{m}$ is the cost of a new machine; tок is a payback time; is the service life by maximum accumulated profit; $t S \Pi=0$ is the service life, when the costs of machine maintenance would consume all the profit received; $t_{\text {opt }}^{\Pi_{\max }}$ is the optimum service life by maximum value of accumulated profit margin.

Analysis of cost efficiency level of machine operation can reveal additional information on determination of its service life:

as this value is one of the main economic indicators. If the lower value $R_{\min }$ is set, for example, 0.3 (Figure 3 ),

$$
R(t)=\Pi(t) / Z(t) \geq R_{\min },
$$

then the maximum service life $t_{\max }^{R_{\operatorname{mix}}}$ can be obtained under the condition of the lowest limit of cost efficiency, which depends on the method of calculation of depreciation expenses.

It seems reasonable to apply models of service life determination by minimum specific costs and maximum profit margin (optimal values are almost equal), if the operating company possesses enough funds for renovation of machinery fleet. In this case, it is possible to gain a significant revenue from the sale of machinery (the market value of machinery decreases by about $20 \%$ per year from the current market value). The model of minimum level of cost efficiency is applicable for companies experiencing shortage of funds for purchase of new equipment.

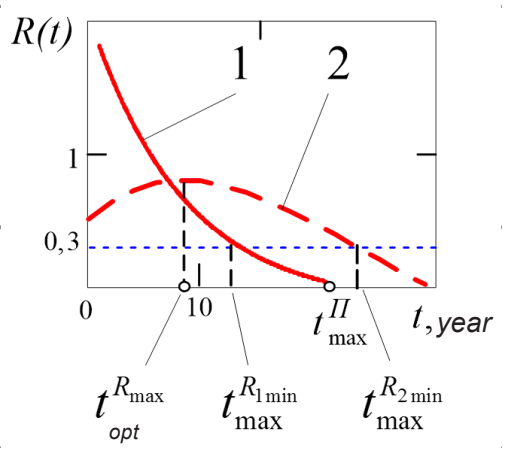

Figure 3. Determination of service life by the level of cost efficiency: $t_{\max }^{R_{\min }}, t_{\max }^{R_{2 \min }}$ is the service life by the lowest standard limit of cost efficiency (0.3); $t_{\text {opt }}^{R_{\max }}$ is optimum service life by maximum of cost efficiency $R_{\max }$; lines 1 and 2 comply with uniform and accelerated (under the factor of 2) methods of calculation of depreciation expenses

\section{Use of TRIM application for analysis and predic- tion of machine operating time}

Parameters $\beta_{t}$ and $\beta_{z}$ depend on the quality of machinery, operation conditions, and the level of operation and maintenance system. Each item of machinery has its own specific parameters. Parameters $\beta_{t}$ and $\beta_{z}$ are calculated by the analysis of statistical information. TRIM application can be used to collect data for calculation of $\beta_{t}$ (Figure 4). Accounting data can be applied to calculate the costs (Repin et al. 2008; Repin, Bondarenko, 2012).

According to values $T_{p}(t)$ from the analysis area collected during the observation period of $n$ years, for example, five years (Figure 5), average value $\beta_{t a v}$ can be obtained:

$$
\beta_{\mathrm{ti}}=\frac{-\ln \left[\mathrm{T}_{\mathrm{P}}(\mathrm{i}) / \mathrm{T}_{\mathrm{P}}(1)\right]}{\mathrm{i}}, \quad \beta_{t a v}=\frac{\sum_{i=2}^{n} \beta_{t i}}{i}
$$

Operation time of the successive years is predicted by value $\beta_{t a v}$. Value $\beta_{z a v}$ is determined the same way. An av-

\begin{tabular}{|c|c|c|c|c|c|c|}
\hline$x s$ & \multicolumn{3}{|c|}{ Counter log } & & $\square$ & $x$ \\
\hline & $\triangle \mathbb{B}$ & \multicolumn{2}{|c|}{ 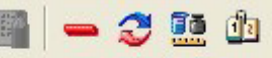 } & \multicolumn{2}{|l|}{$\sqrt{7}$. } & \\
\hline$\nabla$ & Value & Units & Date of input & \multicolumn{2}{|c|}{ Difference } & 스 \\
\hline \multirow[t]{17}{*}{ 1 } & 23517 & Machine hours & 01.01 .2010 & 667 & & \\
\hline & 22850 & Machine hours & 01.12 .2009 & 573 & & \\
\hline & 22277 & Machine hours & 01.11 .2009 & 653 & & \\
\hline & 21624 & Machine hours & 29.10 .2009 & 0 & & \\
\hline & 21624 & Machine hours & 01.10 .2009 & 471 & & \\
\hline & 21153 & Machine hours & 01.09 .2009 & 317 & & \\
\hline & 20836 & Machine hours & 01.08 .2009 & 678 & & \\
\hline & 20158 & Machine hours & 01.07 .2009 & 697 & & \\
\hline & 19461 & Machine hours & 01.06 .2009 & 623 & & \\
\hline & 18838 & Machine hours & 01.05 .2009 & 704 & & \\
\hline & 18134 & Machine hours & 01.04 .2009 & 684 & & \\
\hline & 17450 & Machine hours & 01.03 .2009 & 632 & & \\
\hline & 16818 & Machine hours & 01.02 .2009 & 671 & & \\
\hline & 16147 & Machine hours & 01.01 .2009 & 16147 & & \\
\hline & 0 & Machine hours & 01.01 .2001 & 0 & & \\
\hline & & & & & & $\checkmark$ \\
\hline & \multicolumn{2}{|c|}{15 records are chosen } & \multicolumn{2}{|c|}{ editing } & & \\
\hline
\end{tabular}
erage prediction can be performed if there are data from several single-type machines.

Figure 4. A window of operatin time counter in TRIM application 


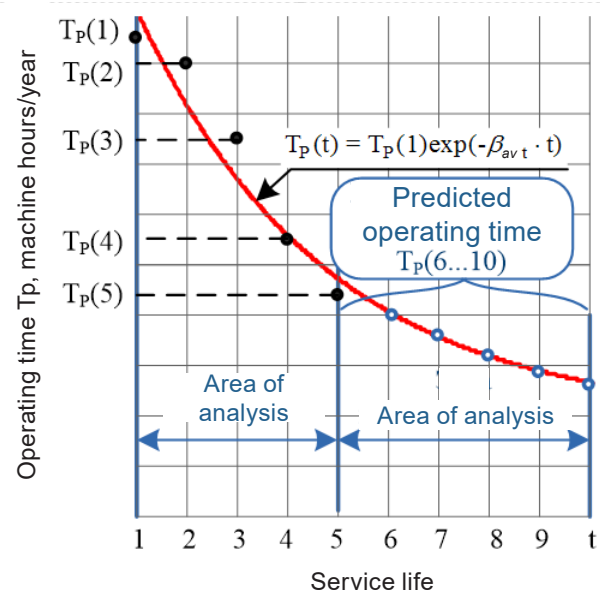

Figure 5. A chart of calculations of $\beta$ tcp and prediction of operating time

It is convenient to export data from TRIM to Excel during analysis. Results of data processing in Excel are given on Figure 6.

\section{Conclusions}

The described method of data processing on operating time of machinery fleet may serve as a basis for predicting of service life not only for machinery, but also for any technical facilities. The value of this method also lies in the fact that it requires a minimum amount of information for prediction, i.e. operating time by periods of operation and maintenance costs.

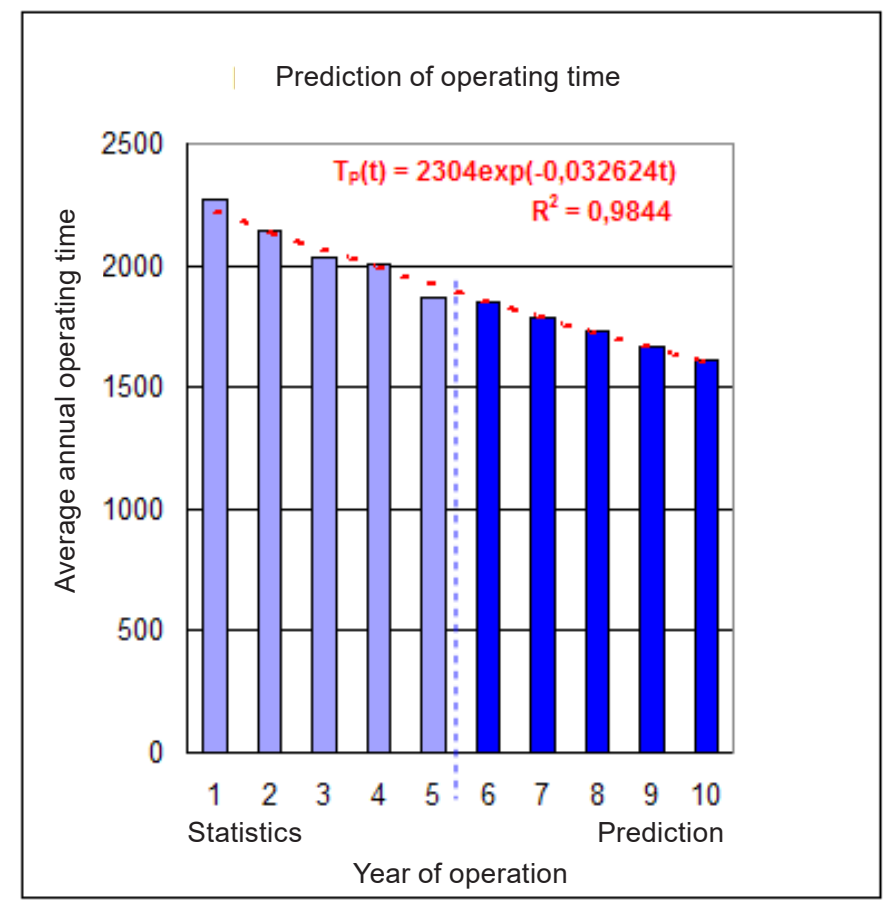

Figure 6. A chart operating time change and a trend line

\section{Acknowledgements}

The study was sponsored by the Russian Humanitarian Science Foundation within the framework of the research project "Development of the method for structuring a transport system by economic and reliability criteria (case study of fleets of plant machinery and vehicles)", project No. 15-02-00512.

\section{References}

Bujaczek R, Sławiński K, Grieger A(2013) Agricultural Machines Maintenance And Repair Services In Western Pomerania. Technical Sciences, 16(1): 13-18. See http://www.uwm.edu.pl/wnt/technicalsc/tech_16_1/b02.pdf (accessed 10.05.2016).

Chernyavsky A, Shadchin A (2010) Evaluation of reliability of low damage probability calculations for unitary structures. Journal of Machinery Manufacture and Reliability, 39(4): 402-406.

GOSSTROI ROSSII (GOSUDARSTVENNYI KOMITET ROSSIISKOI FEDERATSII PO STROITEL"STVU I ZhILIShchNO-KOMMUNAL"NOMU KOMPLEKSU) (1999) MDS 81-3.99: Metodicheskie ukazaniya po razrabotke smetnykh norm i rastsenok na ekspluatatsiyu stroitel'nykh mashin i avtotransportnykh sredstv [Guidelines for Development of Estimate Standards and Prices for Operation of Building Machines and Vehicles]. GOSSTROI ROSSII, Moscow, RF (in Russia).

Makhutov N, Reznikov D (2015) Application of scenario analysis in the assessment of structural reliability of complex technical systems. Journal of Machinery Manufacture and Reliability, 44(8): 675-686.

Protasov A, Nikolaychuk O (2011) Applying the finite-element method for evaluating the reliability of mechanical systems. Journal of Machinery Manufacture and Reliability, 40(1): 27-30.

Repin S (2015) Renewal Methods of Construction Machinery According to Technical and Economic Indicators. Applied Mechanics and Materials, 725-726: 990-995.

Repin SV, Bondarenko AV (2012) Optimizatsiya periodichnosti zamen uzlov transportnykh i tekhnologicheskikh mashin na osnove informatsii po dinamike parametrov ikh tekhnicheskogo sostoyaniya [Optimization of Frequency of Component Overhauling for Transport and Production Machines Taken the Information on Dynamics of Their Technical Condition]. Vestnik grazhdanskikh ingenerov [Bulletin of Civil Engineers], 2(31): 236-243. 
Repin SV, Rulis KV, Zazykin AV, Krupin SA (2012) Metodologija obespechenija rabotosposobnosti transportno-tehnologicheskih mashin i kompleksov sredstvami tehnicheskoj jekspluatacii [Methods of efficient maintenance of transport and production machines and systems with the help of technical service means]. Monograph. SPSUACE, Saint Petersburg, RF (in Russian).

Repin SV, Rulis KV, Zazykin AV. Khovalyg NK (2008) Metodika primenenija informacionnoj avtomatizirovannoj sistemy upravlenija tehnicheskoj jekspluataciej stroitel'nyh mashin i avtotransporta [The method of application of automated information system for management of maintenance and operation of construction machines and vehicles]. SPSUACE, Saint Petersburg, RF (in Russian).

Repin SV, Zazykin AV, Evtyukov SS (2016) Nadezhnost' i jeffektivnost' transportno-tehnologicheskih mashin [Efficiency and Reliability of Plant Machinery and Vehicles]. Publishing House Petropolis, St. Petersburg, RF (in Russian).

Shao-Fei Jiang, Da-Bao Fu, Si-Yao Wu (2014) Structural Reliability Assessment by Integrating Sensitivity Analysis and Support Vector Machine. Mathematical Problems in Engineering, 2014. See http://dx.doi.org/10.1155/2014/586191 (accessed at 10.05.2016)

Smith P (2003) Valve Selection Handbook: Engineering Fundamentals for Selecting the Right Valve Design for Every Industrial Flow Application. Gulf Professional Publishing. 